\title{
Metabolically healthy obesity: facts and fantasies
}

\author{
Gordon I. Smith, Bettina Mittendorfer, and Samuel Klein \\ Center for Human Nutrition, Washington University School of Medicine, St. Louis, Missouri, USA.
}

\begin{abstract}
Although obesity is typically associated with metabolic dysfunction and cardiometabolic diseases, some people with obesity are protected from many of the adverse metabolic effects of excess body fat and are considered "metabolically healthy." However, there is no universally accepted definition of metabolically healthy obesity (MHO). Most studies define MHO as having either $\mathbf{0}, \mathbf{1}$, or $\mathbf{2}$ metabolic syndrome components, whereas many others define MHO using the homeostasis model assessment of insulin resistance (HOMA-IR). Therefore, numerous people reported as having MHO are not metabolically healthy, but simply have fewer metabolic abnormalities than those with metabolically unhealthy obesity (MUO). Nonetheless, a small subset of people with obesity have a normal HOMA-IR and no metabolic syndrome components. The mechanism(s) responsible for the divergent effects of obesity on metabolic health is not clear, but studies conducted in rodent models suggest that differences in adipose tissue biology in response to weight gain can cause or prevent systemic metabolic dysfunction. In this article, we review the definition, stability over time, and clinical outcomes of MHO, and discuss the potential factors that could explain differences in metabolic health in people with $\mathrm{MHO}$ and MUO - specifically, modifiable lifestyle factors and adipose tissue biology. Better understanding of the factors that distinguish people with MHO and MUO can produce new insights into mechanism(s) responsible for obesity-related metabolic dysfunction and disease.
\end{abstract}

\section{Introduction}

Obesity is often associated with a constellation of metabolic abnormalities, including insulin resistance, prediabetes, atherogenic dyslipidemia (high plasma triglyceride [TG] and low HDL-cholesterol [HDL-C] concentrations), nonalcoholic fatty liver disease, and the metabolic syndrome, which are important risk factors for type 2 diabetes (T2D) and cardiovascular diseases (CVDs) (1, 2). However, not all people with obesity have metabolic complications, raising the question of whether those who are metabolically healthy represent a unique subset of people with obesity or are simply a group that is in transition to developing metabolically unhealthy obesity (MUO) later. In this article, we explore the premise that very few people with obesity are truly metabolically healthy, and evaluate putative modifiable factors (diet, physical activity, and sleep) and adipose tissue factors involved in determining the metabolic effects of excessive adiposity. To this end, we will provide a background to review the definition, prevalence, stability, and clinical outcomes of metabolically healthy obesity (MHO), followed by a discussion of potential factors that could explain the differences in metabolic health in people with $\mathrm{MHO}$ and MUO.

\section{Definition of metabolically healthy obesity}

There is no universally accepted standard for defining MHO, and more than 30 different definitions have been used in different studies (ref. 3 and Table 1). In most studies, MHO was defined as

Conflict of interest: SK is a shareholder of Aspire Bariatrics, receives research funding from Merck Sharp \& Dohme Corp. and Janssen Pharmaceuticals, and has served as a consultant for Pfizer, Novo Nordisk, and Merck Sharp \& Dohme Corp.

Copyright: (c) 2019, American Society for Clinical Investigation.

Reference information: J Clin Invest. 2019;129(10):3978-3989.

https://doi.org/10.1172/JCI129186. having $\leq 2$ of the following five metabolic syndrome components: high systolic and diastolic blood pressures, high plasma TG concentration, low HDL-C concentration, high fasting blood glucose, and a large waist circumference; or $\leq 1$ abnormal component excluding waist circumference (4). Additional criteria, including high plasma total cholesterol, LDL-cholesterol, and C-reactive protein concentrations, 2-hour blood glucose concentrations during an oral glucose tolerance test, and indices of insulin sensitivity/resistance (based on the homeostasis model assessment of insulin resistance [HOMA-IR] score [ref. 5], the Matsuda index [an index of whole-body insulin sensitivity] [ref. 6], the glucose infusion rate during a hyperinsulinemic-euglycemic clamp procedure [HECP] [ref. 7], and the insulin suppression test [ref. 8]), have also been used to determine MHO (9-24). In some studies, even people with impaired glucose tolerance, T2D, and history of CVD were considered metabolically healthy because they did not have a sufficient number of the specified metabolic abnormalities to be identified as MUO $(15,25-28)$. Accordingly, people who are reported as having $\mathrm{MHO}$ are often not truly healthy, but simply have fewer cardiometabolic abnormalities than those defined as MUO. Therefore, a more rigorous and universally accepted definition of $\mathrm{MHO}$ is needed to determine the true prevalence and longterm consequences of $\mathrm{MHO}$ and to conduct studies elucidating the mechanisms that protect some people with obesity from the adverse metabolic effects of excess body fat.

We propose a set of robust criteria to identify people with MHO (Table 2), based on (a) the absence of cardiometabolic diseases, (b) a healthy cardiometabolic blood profile, (c) normal blood pressure, (d) normal intrahepatic TG content, and (e) normal insulin sensitivity. We have divided these criteria into those that can be readily obtained in a typical outpatient clinical setting (basic criteria) and those that require more sophisticated testing 


\section{Table 1. Examples of variability in criteria used to identify metabolically healthy obesity}

\section{Cutoff for abnormal values}

Blood pressure (mmHg)

\section{$\geq 130 / 85$ \\ $>130 / 85$ \\ $>140 / 90$}

Blood pressure medications

Fasting TC (mg/dL)

$\geq 150$

Total cholesterol (mg/dL)

$\geq 200$

LDL-cholesterol (mg/dL)

$\geq 130$

HDL-cholesterol (mg/dL)

$<40$ in men or $<50$ in women

$<50$ in men and women

$<40$ in men and women

Lipid medications

Fasting TC/HDL-cholesterol ratio

$>1.65$ in men or $>1.32$ in women

Fasting glucose (mg/dL)

$\geq 100$

$>100$

$\geq 126$

100-125

Clucose 2-h into oral glucose tolerance test (mg/dL)

\section{$\geq 200$}

Diabetes medications

Waist circumference $(\mathrm{cm})$

$>102$ in men or $>88$ in women

HOMA-IR

$\geq 75$ th percentile in study population

$>1.95$

$\geq 2.5$

$>5.13$ (i.e., $\geq 90$ th percentile in study population)

c-reactive protein $(\mathrm{mg} / \mathrm{L})$

$\geq 90$ th percentile in study population

Metabolically healthy

$\begin{array}{cccc}\begin{array}{c}\text { Wildman } \\ (9)\end{array} & \begin{array}{c}\text { Karelis } \\ (10)\end{array} & \begin{array}{c}\text { Aguilar-Salinas } \\ (12)\end{array} \\ \text { X } & - & - & \text { Ly } \\ - & - & - & \\ - & - & X & \\ X & - & X & X\end{array}$

Lynch
(183)

\section{Meigs}

Meigs

(11)

Calori

$\begin{array}{cccc}- & X & - & - \\ x & - & - & - \\ - & - & - & - \\ X & X & - & -\end{array}$

$\begin{array}{llllll} & x & - & - & x\end{array}$

- $\quad x$

X

$-\quad x$

X

$\mathrm{X}$
-
-
$\mathrm{X}$

-
-
-

-
-
-

-
-
-
$X$

$x$

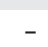

$X$

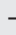

$-$

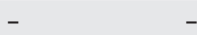

$-$
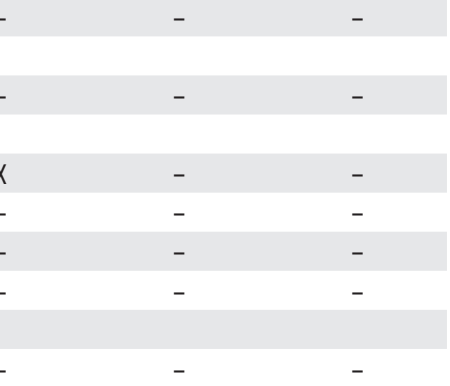

$\begin{array}{lll}X & - & - \\ - & - & - \\ - & - & X \\ - & - & -\end{array}$

-
-
-
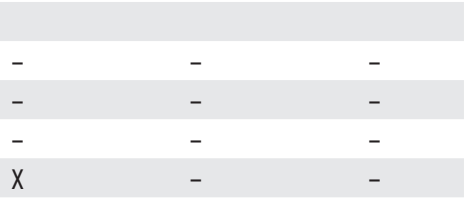

X

$\begin{array}{ll}- & x \\ - & x\end{array}$

$\begin{array}{ll}X & - \\ X & X\end{array}$

$-\quad-$

$-$

$-\quad-$
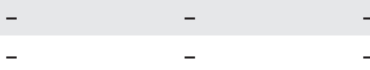

$X$
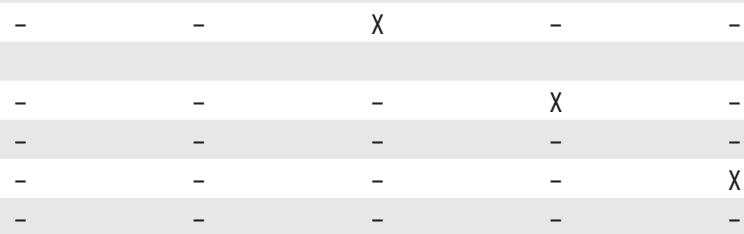

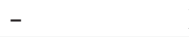
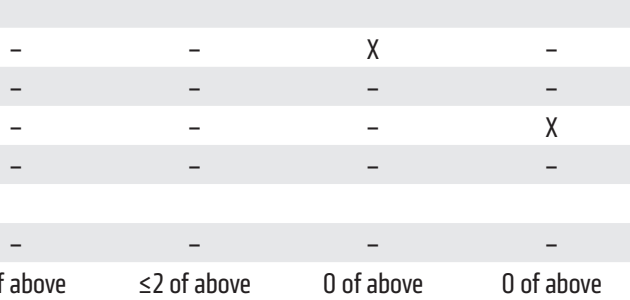

Examples of other criteria used to identify MHO include: (a) Absence of hypertension, dyslipidemia, type 2 diabetes, and cardiovascular disease (82). (b) $\leq 2$ of the National Cholesterol Education Program (NCEP) adult treatment panel (ATP) III metabolic syndrome criteria: waist circumference $>102 \mathrm{~cm}$ in men and $>88 \mathrm{~cm}$ in women; systolic blood pressure $\geq 135 \mathrm{mmHg}$ or diastolic blood pressure $\geq 85 \mathrm{mmHg}$; fasting plasma glucose concentration $\geq 110 \mathrm{mg} / \mathrm{dL}$; $\mathrm{HDL}-\mathrm{C}$ concentration $<40 \mathrm{mg} / \mathrm{dL}$ in men and $<50 \mathrm{mg} / \mathrm{dL}$ in women; fasting plasma TC concentration $\geq 150 \mathrm{mg} / \mathrm{dL}$; or treatment with antihypertensive, lipidlowering, or glucose-lowering medications (4). (c) $\leq 2$ of the NECP ATP III metabolic syndrome criteria revised by the American Heart Association/National Heart, Lung, and Blood Institute (AHA/NHLBI) scientific statement (184) to redefine abnormal fasting glucose concentration as $\geq 100 \mathrm{mg} / \mathrm{dL}$. (d) $\leq 2$ of the AHA/NHLBI metabolic syndrome criteria revised to define waist circumference cutoff values based on population and country-specific standards (185). (e) $\leq 1$ metabolic syndrome criteria excluding waist circumference $(33,38$ ). (f) Zero metabolic syndrome components, except for waist circumference (50, 186). (g) Plasma C-reactive protein concentration $<3 \mathrm{mg} / \mathrm{L}$ in addition to different metabolic syndrome components with or without criteria for HOMA-IR and LDL-cholesterol $(16,60)$. (h) HOMA-IR values: $\leq 2.7$ (16), lowest tertile in participants with obesity $(187),<25$ th percentile (HOMA-IR $\leq 1.27)(43)$ or $<90$ th percentile (47) of participants without diabetes. (i) "Insulin sensitive," defined as OGTT-derived Matsuda index (6) $>2.1$ (18); or as $\geq 75$ th percentile of people with obesity (19); or as glucose infusion rate during a hyperinsulinemic-euglycemic clamp procedure of $>8 \mathrm{mg} / \mathrm{kg}$ lean body mass/min at insulin infusion rate of $40 \mathrm{mU} / \mathrm{m}^{2}$ body surface area/min (20), $>70 \mu \mathrm{mol} / \mathrm{kg}$ body mass $/ \mathrm{min}$ at insulin infusion rate of $40 \mathrm{mU} / \mathrm{m}^{2}$ body surface area/min (21), $\geq$ upper tertile $\left(\geq 10.5 \mathrm{mg} / \mathrm{kg}\right.$ fat-free mass $/ \mathrm{min}$ ) at insulin infusion rate of $50 \mathrm{mU} / \mathrm{m}^{2}$ body surface area/min (22), or $\geq$ upper quartile ( $\geq 12.62 \mathrm{mg} / \mathrm{kg}$ fat-free $\mathrm{mass} / \mathrm{min}$ ) at insulin infusion rate of $75 \mathrm{mU} / \mathrm{m}^{2}$ body surface area/min (23) of people with obesity in the study; or as steady-state glucose concentration $<100 \mathrm{mg} / \mathrm{dL}$ during fixed-rate infusion of octreotide, glucose, and insulin (24). 


\section{Table 2. Proposed criteria for defining metabolically healthy obesity}

\section{Basic criteria:}

Absence of diagnosis or therapy of

cardiometabolic diseases

Absence of prediabetes, T2D, hypertension, dyslipidemia, NAFLD, CKD, or CVD; or treatment with blood pressure, lipid, or diabetes medications

\section{Healthy cardiometabolic profile:}

Fasting TC

HDL-C

Fasting glucose

2-hour OGTT glucose

Blood pressure

\section{Advanced criteria:}

Intrahepatic lipid content (for those not already diagnosed as having NAFLD)

Insulin sensitivity
$<95 \mathrm{mg} / \mathrm{dL}$

$\geq 40 \mathrm{mg} / \mathrm{dL}$ in men and $\geq 50 \mathrm{mg} / \mathrm{dL}$ in women

$<100 \mathrm{mg} / \mathrm{dL}$

$<140 \mathrm{mg} / \mathrm{dL}$

$<130 / 85 \mathrm{mmHg}$

$<5 \%$ of liver volume by imaging or $<5 \%$ of hepatocytes with intracellular TG by histology

$\mathrm{CIR}>8 \mathrm{mg} / \mathrm{kg} \mathrm{FFM} / \mathrm{min}$ during an HECP

(insulin infusion rate: $40 \mathrm{mU} / \mathrm{m}^{2} / \mathrm{min}$ )

CKD, chronic kidney disease; CVD, cardiovascular disease; FFM, fat-free mass; GIR, glucose infusion rate; NAFLD, nonalcoholic fatty liver disease; HECP, hyperinsulinemiceuglycemic clamp procedure; OGTT, oral glucose tolerance test; T2D, type 2 diabetes.

available in a research setting (advanced criteria). We propose a lower plasma TG concentration "cut-point" than that used for diagnosing the metabolic syndrome (i.e., $<95 \mathrm{mg} / \mathrm{dL}$ vs. $<150$ $\mathrm{mg} / \mathrm{dL}$ ), based on the plasma TG concentration that marks the point of transition from large buoyant LDL particles to highly atherogenic, small, dense LDL particles (29). We also propose the inclusion of an assessment of insulin sensitivity, defined as the glucose infusion rate needed to maintain euglycemia during an HECP, because many people with obesity who are resistant to insulin can have a normal fasting plasma glucose concentration and normal oral glucose tolerance due to a compensatory increase in plasma insulin (30). We chose a glucose infusion rate cutoff value that was used previously to define MHO (20) and is similar to the mean value reported in people with a BMI of $25 \mathrm{~kg} /$ $\mathrm{m}^{2}$ who are metabolically healthy (31).

\section{Prevalence of metabolically healthy obesity}

The prevalence of MHO depends on the criteria used to define metabolic health, whether people with T2D or CVD were excluded from the cohort a priori, and the sex, age, BMI range, and racial or ethnic background of the study population. Differences in these variables are likely responsible for the large variability in reported prevalence, ranging from $6 \%$ (32) to $60 \%$ (33) of adults with obesity when the criteria for metabolic health were based on measured variables (see Supplemental Tables 1-4; supplemental material available online with this article; https://doi.org/10.1172/ JCI129186DS1), and up to 75\% when based primarily on selfreported data (34). In general, MHO is more common in women than in men (35-38), in younger than in older adults $(35,36,39)$, in people with BMIs less than $35 \mathrm{~kg} / \mathrm{m}^{2}$ than in people with BMIs of $35 \mathrm{~kg} / \mathrm{m}^{2}$ or higher (40), and in people of European ancestry than in those from Africa, South America, and South Asia (Indian ancestry) $(39,41)$. An estimate of the prevalence of MHO based on the stringency of selection criteria from studies conducted in North American and European cohorts is shown in Figure 1 and
Supplemental Tables 1-4. The prevalence of MHO, defined as "normal" insulin sensitivity (based on the HOMA-IR score) and absence of any metabolic syndrome components (excluding waist circumference), is approximately $7 \%$, whereas half of all people with obesity can be classified as MHO when defined as $\leq 2$ metabolic syndrome components (including waist circumference). However, it is likely that these results overestimate the prevalence of MHO in the general population, because many studies excluded people with existing cardiometabolic diseases, such as T2D and $\operatorname{CVD}(9,11,13,28,42-44)$.

\section{Stability of metabolically healthy obesity over time}

The normal decline in metabolic health associated with increasing age, the metabolic insult of prolonged excess adiposity, and the tendency to gain weight throughout middle age likely influence the stability of MHO. The data from longitudinal studies suggest that approximately $30 \%$ to $50 \%$ of people with $\mathrm{MHO}$ convert to MUO after 4 to 20 years of follow-up $(25,28,42,45$ 48). The major factors associated with the conversion of MHO to MUO are a decline in insulin sensitivity and an increase in fasting blood glucose (49). The risk of transitioning from MHO to MUO is greater in those with a high BMI, older age, evidence of more severe metabolic dysfunction (i.e., number of abnormal metabolic criteria and values that are closer to the upper limit of the normal range, and the presence of hepatic steatosis) $(28,50-52)$, a poor lifestyle index (a composite of diet composition, leisure time physical activity, and cigarette smoking) (53), and weight gain during the observation period $(54,55)$.

\section{Clinical outcomes of metabolically healthy versus unhealthy obesity}

In general, the risks of T2D, CVD, and all-cause mortality are greater in people with MUO than in those with MHO and greater in those with $\mathrm{MHO}$ than in those who are metabolically healthy and lean (MHL) (14, 28, 56-60). Moreover, the risks of these adverse outcomes are directly related to the number and severity of metabolic abnormalities (57, 61-66).

\section{Type 2 diabetes}

The data from most studies show that the risk of developing T2D is 5- to 20-fold greater in people with MUO than in those who are MHL (56). The risk of developing T2D is much lower in those with MHO than MUO, but is still about 4-fold greater than in those who are MHL (56), and is directly related to the number of metabolic abnormalities at baseline (61-63). In studies with a 6-year follow-up, the risk of developing T2D relative to MHL individuals was still increased in people with $\mathrm{MHO}$ without any metabolic syndrome components at baseline (61), but was not increased when metabolic status remained stable throughout the study (67).

\section{Cardiovascular disease}

The risk of CVD events (new-onset angina, fatal and nonfatal myocardial infarction, sudden cardiac death, fatal and nonfatal 


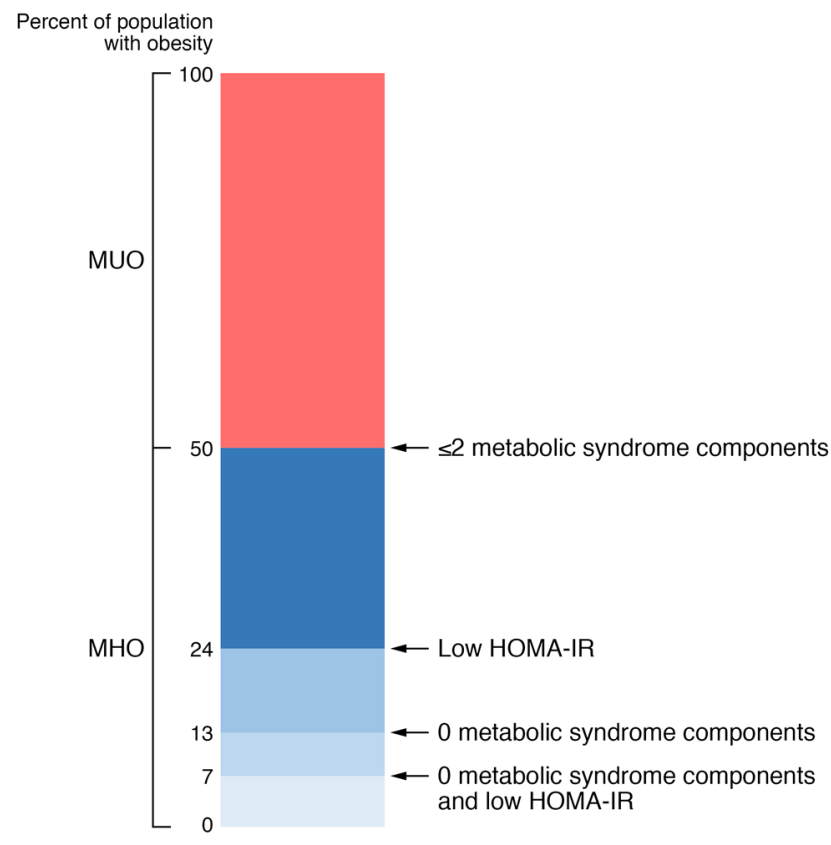

Figure 1. Estimated prevalence of metabolically healthy and metabolically unhealthy obesity among people with obesity in North America and Europe based on the number of metabolic syndrome criteria and an assessment of insulin sensitivity (using the homeostasis model assessment of insulin resistance [HOMA-IR] score). Data were derived from 33 studies involving a total of 123,548 people with obesity as described in the Supplemental Material (available online with this article; https://doi. org/10.1172/JCI129186DS1).

heart failure, and peripheral vascular disease) is lower in people with MHO than in those with MUO, but is still higher in people with MHO than in those who are MHL (57-59). A meta-analysis that pooled data from 18 studies followed over a median of 10 years found that the risk of CVD events was about $50 \%$ greater in people with MHO at baseline than in people who were MHL (14). The risk of developing CVD events is directly associated with the number of metabolic abnormalities at baseline (57) and whether the MHO phenotype remains stable or converts to MUO (28). For example, in one study, the risk of CVD events in participants who maintained a stable MHO phenotype over a median of 12 years was not different from that in participants who were MHL (28).

\section{All-cause mortality}

The risk of all-cause mortality is less in people with MHO than in people with MUO (60). The risk of all-cause mortality in people with MHO relative to those who are MHL depends on the number and severity of metabolic abnormalities and the stability of metabolic health (64-66). The combined data from five large cohort studies that followed participants for an average of 13 years found that people with $\mathrm{MHO}$ and no metabolic syndrome components (excluding waist circumference) did not have an increased risk of all-cause mortality compared with the MHL group; however, the risk of all-cause mortality was greater in participants with MHO versus MHL when participants with one abnormal metabolic risk factor (excluding waist circumference) were included in the MHO group (66).

\section{Selected characteristics of metabolically healthy and unhealthy obesity}

The characteristics that have been associated with MUO are shown in Figure 2. Among these features, multiorgan insulin resistance (impaired insulin-mediated suppression of hepatic glucose production, suppression of adipose tissue lipolytic activity, and stimulation of muscle glucose uptake) is likely the most important underlying factor responsible for the development of cardiometabolic diseases (68). In people without diabetes, whole-body insulin sensitivity, assessed with the HECP, is inversely correlated with BMI; however, there is considerable heterogeneity in insulin sensitivity at any given BMI value so that a small subset of people with obesity are as insulin sensitive as people who are lean $(31,69)$. Insulin sensitivity is greater in people with MHO than in those with MUO, and many participants identified as having $\mathrm{MHO}$ are more insulin resistant than those who are MHL, manifested by greater fasting plasma insulin concentrations, blood glucose concentrations during an oral glucose tolerance test, and HOMA-IR values $(9,27,70-72)$. The factors responsible for the greater preservation of insulin action in people with MHO than in those with MUO are not clear, but could be related to differences in potentially modifiable lifestyle factors and alterations in adipose tissue biology (73). In this section we review each of these areas with a major focus on adipose tissue biology.

\section{Lifestyle factors}

Diet. The relationship between dietary intake and metabolic health has been evaluated in large population studies by using the food frequency questionnaires or 24-hour dietary recall data. The ability of these methods to reliably assess dietary intake has been questioned $(74,75)$. The results from most studies do not show a difference in total dietary energy intake or macronutrient distribution between people with MHO and MUO (76-78). In addition, data from the US National Health and Nutrition Examination Survey showed no difference in diet quality, assessed as the consumption of Mediterranean-style and DASH-style diets, between people with MHO and MUO (79). A higher total Healthy Eating Index score, which assesses diet quality in relation to the 2005 US National Dietary Guidelines, was found in MHO than in MUO women who were 19-44 years old, but this score was not different in women with $\mathrm{MHO}$ and MUO who were $45-85$ years old or in adult men with $\mathrm{MHO}$ and $\mathrm{MUO}(80)$. There is evidence from some $(76,77,80-82)$ but not all $(27,77)$ studies that the consumption of specific types of foods differs between MHO and MUO groups; MHO was associated with a lower intake of sugar, sugar-sweetened beverages, and saturated fat and a higher intake of whole fruits, whole grains, and protein from vegetable sources.

Physical activity and cardiorespiratory fitness. Increased physical activity improves insulin sensitivity and metabolic syndrome abnormalities (83). The amount and intensity of physical activity in MHO and MUO populations have been studied by the doubly labeled water method, accelerometry, and activity questionnaires. No differences in total daily energy expenditure or energy expended during physical activity, measured by the doubly labeled water method, were detected between people with MHO and MUO $(20,84)$. In contrast, studies that measured physical activity by using accelerometers or questionnaires showed that people with 


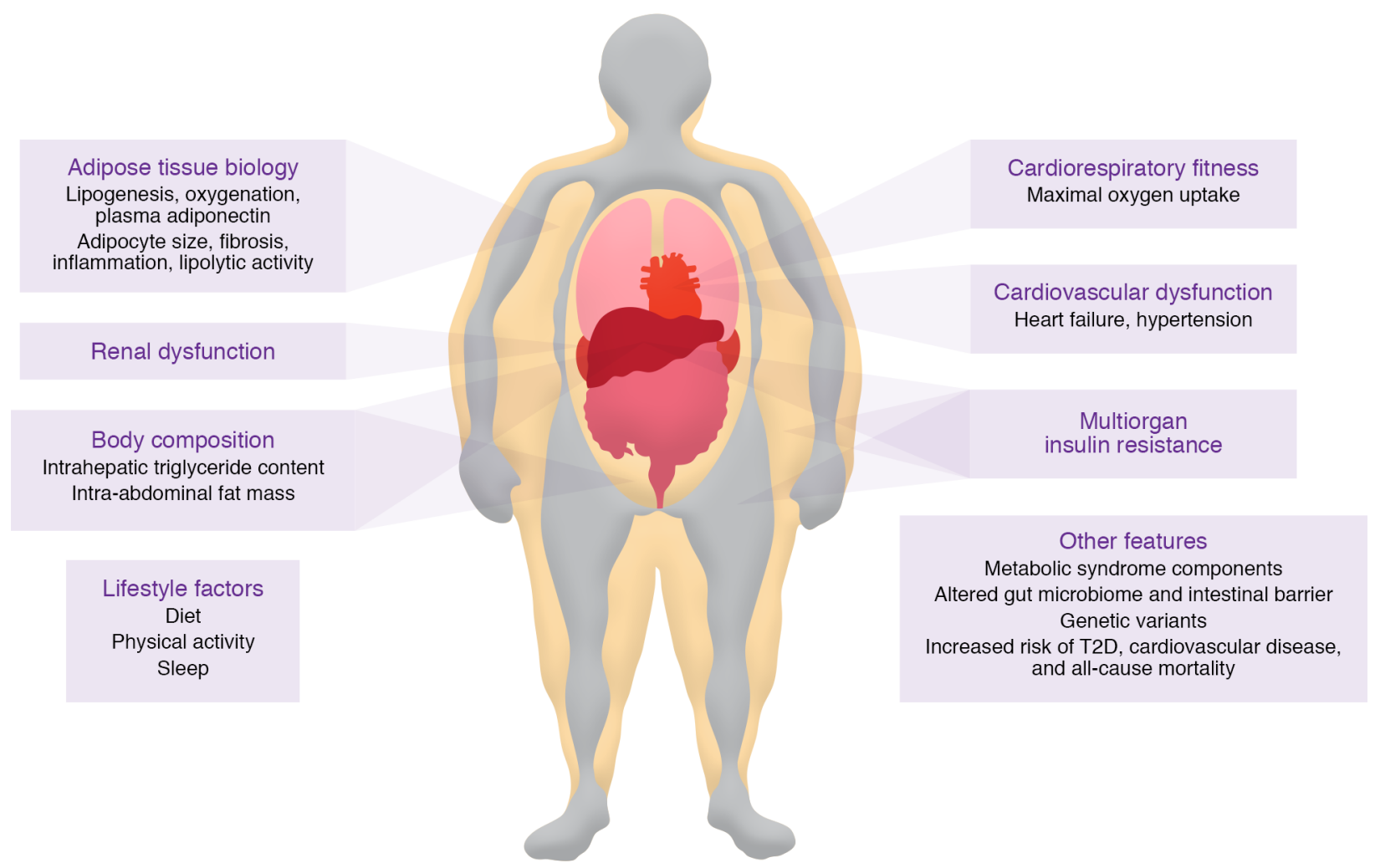

Figure 2. Putative characteristics of people with metabolically unhealthy obesity that are distinct from those of people with metabolically healthy obesity. However, the evidence to support a difference in many of these characteristics between people with MUO and MHO is not definitive because of inadequate data or conflicting results from different studies.

MHO spend more time in moderate to vigorous physical activities and less time in sedentary activities than people with MUO (35, 85-87). The results from a meta-analysis that pooled data from 15 studies found that cardiorespiratory fitness, assessed as maximum oxygen consumption during exercise, was greater in people with MHO than in those with MUO (87), but the average difference between groups was very small (1-2 $\mathrm{mL} / \mathrm{kg} / \mathrm{min})$.

Sleep. Insufficient sleep duration and poor sleep quality have adverse effects on metabolic function (88) and are associated with obesity $(89,90)$. The results from nearly all studies that have assessed sleep duration and quality in people with MHO and MUO are not adequate to reliably evaluate potential differences between people with $\mathrm{MHO}$ and MUO, because the data are derived from questionnaires rather than direct assessments of sleep duration and quality. In general, sleep duration and the proportion of short sleepers ( $<7$ hours per day) were not significantly different in people with MHO and those with MUO (72, 85, 91-93).

\section{Adipose tissue biology}

The expansion of adipose tissue and TG mass with weight gain (a) is not uniformly distributed among different adipose tissue depots and the liver; (b) is due to an increase in adipocyte size or adipocyte number, or both; (c) requires adequate blood supply to maintain tissue oxygenation; (d) promotes extracellular matrix (ECM) remodeling to provide the scaffolding needed to support the expanded adipocyte mass; (e) causes an increase in adipose tissue-resident immune cells and both adipose tissue and system- ic markers of inflammation; (f) affects adipocyte lipolytic activity and the rate of release of fatty acids into the circulation; and (g) alters the production of adiponectin, the major adipocyte secretory protein involved in regulating insulin sensitivity.

Body composition. Percentage body fat is not different in people with MHO and MUO when the groups are matched on BMI and sex (19-21, 23, 94). However, there are marked differences in adipose tissue distribution and intrahepatic TG content between MHO and MUO cohorts. People with MHO have less intraabdominal adipose tissue (IAAT) than people with MUO (21, 23, 76, 95-97), but still have two to three times more IAAT than people who are MHL $(19,22)$. Although women with MHO tend to have a greater amount of lower-body (subcutaneous thigh or leg) fat mass than women with MUO $(20,48,95,96)$, lower-body fat mass is not different between men with MHO and MUO $(48,96)$. Intrahepatic TG content is greater in people with MUO than in those with MHO (98), and those with steatosis have greater multiorgan insulin resistance (99) and higher plasma TG concentrations (100) than those with normal intrahepatic TG content, even when matched on BMI, percentage body fat, and IAAT volume (101). Taken together, these data show that excess adiposity per se is not responsible for the differences in metabolic health between people with MHO and MUO, but differences in adipose tissue distribution distinguish between MHO and MUO phenotypes.

Adipogenesis and lipogenesis. Studies that assessed adipogenesis/lipogenesis in people with MHO and MUO have focused primarily on the subcutaneous abdominal adipose tissue (SAAT) 
depot. The relationship between adipogenesis (i.e., proliferation and differentiation of preadipocytes) in SAAT and metabolic health is unclear. Adipogenic capacity in SAAT, assessed by in vitro differentiation assays and expression of genes involved in preadipocyte proliferation and differentiation, is greater in people with MHO than in those with MUO (102-105). However, adipocyte proliferation rates, determined in vivo by measurement of the incorporation of ingested deuterium into the DNA of adipocytes isolated from SAAT, have been reported as either not different (106) or lower (107) in people who were overweight/obese and insulin sensitive than in people who were overweight/obese and insulin resistant. The capacity for lipogenesis in SAAT, assessed as expression of genes involved in lipogenic pathways (CD36, GLUT4, ChREBP, FASN, and MOGAT1), is greater in people with MHO than MUO $(101,102,108,109)$. Moreover, the expression of these genes is positively correlated with insulin sensitivity (108, 109), and increases more after moderate weight gain in people with MHO than MUO (110). Collectively, these data refute the notion that impaired adipogenesis contributes to insulin resistance in people with MUO (111), but demonstrate that increased adipose tissue gene expression of lipogenic pathways is associated with metabolic health.

Adipocyte size. Adipocyte size is typically measured by one of three methods: (a) histological analysis of adipose tissue; (b) collagenase digestion of adipose tissue to generate free adipocytes that are measured by microscopy; and (c) adipose tissue osmium tetroxide fixation and cell size analysis using microscopy or a Multisizer Coulter Counter. The median adipocyte diameters in SAAT measured by each of these methods correlate with whole-body adiposity (112). However, the frequency of small cells $(20-50 \mu \mathrm{m}$ range) varies considerably among the three methods (112). The highest frequency of these small cells, which are believed to be immature or differentiating adipocytes, but could be large lipidladen macrophages (113), is observed when cell size is assessed by the osmium fixation method $(112,114)$. The results from several studies show an inverse correlation between average or peak subcutaneous abdominal adipocyte size and insulin sensitivity, and that adipocyte size is greater in people with MUO than in those who are metabolically healthier $(21,114-118)$. However, other studies did not detect a difference in average subcutaneous adipocyte size in MHO and MUO participants $(102,105,119)$. Two studies identified two distinct populations of adipocytes based on size and found a higher ratio of small to large subcutaneous abdominal adipocytes in people who were insulin resistant than in those who were insulin sensitive $(102,114)$. In summary, the majority of studies show that mean adipocyte size is smaller in people with $\mathrm{MHO}$ than MUO. However, the observation that adipose tissue contains distinct small- and large-cell populations with variable cell numbers confounds the interpretation of overall mean cell size. Accordingly, more sophisticated analytical methods that quantify adipocyte cell sizes and number are needed.

Oxygenation. The oxygenation of adipose tissue depends on the balance between the rate of oxygen delivery to adipose tissue cells (adipocytes, preadipocytes, mesenchymal stem cells, fibroblasts, vascular endothelial cells, and immune cells) and their rate of oxygen consumption. The delivery of oxygen to adipose tissue is likely lower in people with obesity than in people who are lean because of decreased systemic arterial oxygen content associated with pulmonary dysfunction $(120,121)$, decreased adipose tissue capillary density and perfusion (122-125), an increased number of interstitial immune cells (126), and possibly greater oxygen diffusion distance due to hypertrophied adipocytes and increased ECM content (127). However, the adequacy of adipose tissue oxygenation in people with obesity is not clear, because interstitial adipose tissue oxygen partial pressure $\left(\mathrm{pO}_{2}\right)$, not intracellular $\mathrm{pO}_{2}$, is measured and because of conflicting data from different studies depending on the method used (120, 123-125, 128-130). Studies that used a Clark-type electrode or a fiber optic system to assess interstitial SAAT $\mathrm{pO}_{2}$ in situ found that $\mathrm{pO}_{2}$ was lower in people who are obese than in those who are lean $(123,124,128,129)$. In contrast, studies that used an optochemical sensor to measure $\mathrm{pO}_{2}$ in SAAT interstitial fluid extracted by microdialysis ex vivo found that $\mathrm{pO}_{2}$ was higher in people with obesity than in those who were lean despite decreased adipose tissue blood flow in people with obesity, suggesting decreased adipose tissue oxygen consumption in the obese group $(125,130)$. A direct assessment of arteriovenous oxygen balance across SAAT demonstrated that both oxygen delivery and consumption were decreased in people with obesity compared with those who were lean or overweight; however, obesity was not associated with evidence of adipose tissue hypoxia, assessed as oxygen net balance and the plasma lactate-to-pyruvate ratio across SAAT (120). We are aware of three studies that evaluated interstitial SAAT $\mathrm{pO}_{2}$ in people with $\mathrm{MHO}$ and MUO. Two studies measured $\mathrm{pO}_{2}$ in situ and found that $\mathrm{pO}_{2}$ was greater (128), or not different (129), in the MHO compared with MUO groups. The third study measured $\mathrm{pO}_{2}$ ex vivo in SAAT interstitial fluid extracted by microdialysis and found it was lower in $\mathrm{MHO}$ than in MUO (130). We are not aware of any studies that evaluated metabolic indicators of adipose tissue hypoxia, namely adipose tissue HIF1 $\alpha$ protein content, in people with MHO and MUO. In summary, currently there is not adequate evidence to conclude there is a physiologically important decrease in adipose tissue oxygenation in people with MUO compared with MHO.

ECM remodeling and interstitial fibrosis. The ECM of adipose tissue is composed of structural proteins (primarily collagens I, III, IV, V, and VI) and adhesion proteins (fibronectin, elastin, laminin, and proteoglycans). Compared with people who are lean, people with obesity have increased expression of genes for collagen I, IV, V, and VI and histological evidence of increased fibrosis, particularly pericellular fibrosis in omental adipose tissue and SAAT (131-135). In addition, we recently found that adipose tissue expression of connective tissue growth factor (CTGF), a matricellular protein that regulates tissue fibrosis, is positively correlated with body fat mass and inversely correlated with indices of wholebody, liver, and skeletal muscle insulin sensitivity (136). Adipose tissue expression of collagen genes and collagen content are also inversely correlated with insulin sensitivity in people with obesity, and decrease with weight loss (129, 137-139). These data support the notion that adipose tissue fibrosis is associated with MUO, as has been demonstrated in rodent models (140).

Immune cells and inflammation. Obesity is typically associated with chronic, low-grade, noninfectious inflammation, which has been purported to be a cause of insulin resistance $(141,142)$. It has been proposed that alterations in adipose tissue immune cells 
are an important cause of the chronic inflammation and insulin resistance associated with obesity $(141,143)$. Macrophages are the most abundant immune cell in adipose tissue, and adipose tissue macrophage content is increased in people with obesity compared with people who are lean (126). Moreover, adipose tissue macrophage content and crown-like structures (macrophages surrounding an extracellular lipid droplet) are greater in both SAAT and IAAT in people with MUO than in those with MHO; the increase in macrophage content is primarily due to an increase in M1-like (proinflammatory) macrophages $(21,144-147)$. Differences in adipose tissue proinflammatory $\mathrm{CD}^{+} \mathrm{T}$ lymphocytes between people with $\mathrm{MHO}$ and MUO have also been reported. The percentages of total $\mathrm{CD} 4{ }^{+} \mathrm{T}$ cells that are proinflammatory Th17 and Th22 cells are lower in both SAAT and IAAT in people with MHO than MUO $(22,148)$. In addition, in one study, antiinflammatory $\mathrm{CD}^{+}{ }^{+} \mathrm{Th} 2$ cells in both SAAT and IAAT correlated directly with insulin sensitivity, assessed by the insulin suppression test (149).

In conjunction with the alterations in adipose tissue immune cells, adipose tissue expression of inflammation-related genes is also greater in people with MUO than in those with $\mathrm{MHO}(21,129$, $145,146,150,151)$, but there is inconsistency in the specific genes that are upregulated among studies, and the differences in gene expression markers between MUO and MHO groups are often small $(21,129,145,146,150,151)$. Plasma concentrations of markers of inflammation, primarily C-reactive protein, plasminogen activator inhibitor-1 (PAI-1), IL-6, and TNF- $\alpha$, are either higher in those with MUO than MHO $(21,23,42,96,152-154)$ or not different between the two groups (155-157). The variability in results is likely related to the definitions used to identify MUO and MHO, the specific inflammatory markers evaluated in different studies, and the sample size needed for adequate statistical power because of small mean differences in plasma concentrations between groups.

The variability and small difference in adipose tissue expression of inflammatory markers in people with MHO and MUO and both the variability and small differences in plasma markers of inflammation between people with MUO and MHO question the importance of adipose tissue production and secretion of inflammatory cytokines in mediating the difference in systemic insulin resistance observed in people with MUO and MHO. Nonetheless, it is possible that other immune cell-related mediators, such as adipose tissue macrophage-derived exosomes (158), are involved in the pathogenesis of metabolic dysfunction.

Lipolytic activity. Acute experimental increases in plasma free fatty acid (FFA) concentration, induced by infusion of a lipid emulsion, impair insulin-mediated suppression of hepatic glucose production and insulin-mediated stimulation of glucose disposal in a dose-dependent manner $(159,160)$. However, the influence of endogenous adipose tissue lipolytic activity and plasma FFA concentration on insulin sensitivity in people with obesity is not clear because of conflicting results from different studies. Specifically, the basal rates of FFA release into the systemic circulation and plasma FFA concentration have been reported as either greater $(21,161$, $162)$ or not different $(101,163,164)$ in people who are overweight/ obese and insulin resistant compared with those who are insulin sensitive. The importance of circulating FFA as a cause of insulin resistance in MUO is further questioned by studies that found no difference in basal, postprandial, and 24-hour plasma FFA concen- trations in people with obesity compared with those who are lean and more insulin sensitive $(122,165)$. The reason(s) for the differences between studies are not clear, but could be related to the considerable individual day-to-day variability in FFA kinetics and plasma FFA concentration and differences in compensatory hyperinsulinemia and insulin-mediated suppression of adipose tissue lipolytic rate in people with insulin resistance $(122,165,166)$. Differences in the percentage of women between study cohorts will also affect the comparison of FFA kinetics and concentrations between MHO and MUO groups, because the rate of the appearance of FFA in the bloodstream in relationship to fat-free mass or resting energy expenditure is greater in women than in men $(167,168)$, yet muscle (169) and liver $(170,171)$ insulin sensitivity are greater in women. Taken together, these studies suggest that differences in subcutaneous adipose tissue lipolytic activity do not explain the differences in insulin sensitivity between people with MHO and MUO. However, it is still possible that differences in lipolysis of IAAT and portal vein FFA concentration (172) or differences in the effect of FFA on tissue (muscle or liver) insulin action contribute to the differences in insulin resistance between the two groups.

Adiponectin. Adiponectin, the most abundant protein secreted by adipose tissue, is inversely associated with percentage body fat and directly associated with insulin sensitivity in both men and women (173). Plasma adiponectin concentrations are often higher in people with MHO than MUO (12,174-176). The reasons for the lower adiponectin concentration in MUO than MHO are unclear but could be related to chronic hyperinsulinemia in people with MUO, which suppresses adipose tissue adiponectin production $(177,178)$, thereby generating a feed-forward cycle of decreased adiponectin secretion caused by insulin resistance and increased insulin resistance caused by decreased adiponectin secretion.

\section{Conclusions}

There is considerable heterogeneity in the metabolic complications associated with obesity. About $50 \%$ of people with obesity are metabolically healthy when healthy is defined as the absence of the metabolic syndrome, whereas only approximately $5 \%$ are metabolically healthy when healthy is defined as the absence of any metabolic syndrome components and normal insulin sensitivity assessed by HOMA-IR. The risk of developing cardiometabolic diseases in people with obesity is directly related to the number and severity of metabolic abnormalities. Accordingly, people with MHO are at lower risk of future T2D and CVD than people with MUO, but most people with MHO are at a higher risk than people who are MHL. However, people with MHO who do not have any metabolic abnormalities and remain $\mathrm{MHO}$ over time might not have an increased risk of developing cardiometabolic diseases compared with those who are MHL. These findings support the need for a rigorous and universal definition of $\mathrm{MHO}$ (proposed in Table 2) to allow reliable integration of data from different studies and facilitate research needed to identify the factor(s) involved in protecting some people with obesity from the adverse metabolic effects of excess adiposity.

The precise mechanisms responsible for preserved metabolic health in people with MHO are not known. The studies to date have not demonstrated important differences in lifestyle factors (diet composition, physical activity, and sleep) between MHO and 
MUO. However, this does not mean that lifestyle is not an important regulator of metabolic health, but rather underscores the limitations in the assessment of lifestyle factors and in the definition of MHO in the current studies. It is likely that there is an important genetic contribution to the metabolic phenotype in people with obesity. Although GWAS have identified genetic variants that are associated with increased adiposity in conjunction with a healthy metabolic profile (179), a better understanding of the genetic aspects of MHO will likely provide new insights into the mechanisms responsible for metabolic disease. The influence of the gut microbiome on metabolic health is a rapidly emerging area of research. The potential for adverse and beneficial effects of the gut microbiome on metabolic health could be related to the composition and diversity of the microbiota and the ability of the gut barrier function to prevent leakage of bacteria and bacterial products across the intestine (180-182). In addition, studies conducted in human subjects demonstrate an increase in markers of inflammation and interstitial fibrosis in adipose tissue in people with MUO compared with MUO. However, these studies are not able to determine whether these abnormalities are a cause or a consequence of insulin resistance and related metabolic dysfunction.

The heterogeneity in the metabolic complications associated with obesity has important clinical implications, particularly in the current era of precision medicine and cost-effectiveness. The classification of obesity by BMI status alone does not provide adequate insight into current health status, the potential risk of future adverse clinical outcomes, or who might benefit most from weight loss therapy. The available data suggest that more intensive, and presumably more expensive, weight management therapies should be prioritized for those with MUO over those with MHO. However, this approach requires a more robust diagnosis of $\mathrm{MHO}$ and additional data to understand the relationship between $\mathrm{MHO}$ and the risk of other obesity-related complications, beyond metabolic outcomes alone.

\section{Acknowledgments}

This Review was supported by NIH grants DK115502, DK115400, DK121560, DK56341 (Nutrition Obesity Research Center), and RR024992 (Clinical and Translational Science Award), a grant from the American Diabetes Association (1-18-ICTS-119), and a grant from the Pershing Square Foundation.

Address correspondence to: Samuel Klein, Center for Human Nutrition, Washington University School of Medicine, 660 South Euclid Avenue, Campus Box 8031, St. Louis, Missouri 63110, USA. Phone: 314.362.8708; Email: sklein@wustl.edu.
1. Klein S, Wadden T, Sugerman HJ. AGA technical review on obesity. Gastroenterology. 2002;123(3):882-932.

2. Fabbrini E, Sullivan S, Klein S. Obesity and nonalcoholic fatty liver disease: biochemical, metabolic, and clinical implications. Hepatology. 2010;51(2):679-689.

3. Rey-López JP, de Rezende LF, Pastor-Valero $\mathrm{M}$, Tess BH. The prevalence of metabolically healthy obesity: a systematic review and critical evaluation of the definitions used. Obes Rev. 2014;15(10):781-790.

4. National Cholesterol Education Program (NCEP) Expert Panel on Detection, Evaluation, Treatment of High Blood Cholesterol in Adults (Adult Treatment Panel III). Third Report of the National Cholesterol Education Program (NCEP) Expert Panel on Detection, Evaluation, and Treatment of High Blood Cholesterol in Adults (Adult Treatment Panel III) final report. Circulation. 2002;106(25):3143-3421.

5. Matthews DR, Hosker JP, Rudenski AS, Naylor BA, Treacher DF, Turner RC. Homeostasis model assessment: insulin resistance and betacell function from fasting plasma glucose and insulin concentrations in man. Diabetologia. 1985;28(7):412-419.

6. Matsuda M, DeFronzo RA. Insulin sensitivity indices obtained from oral glucose tolerance testing: comparison with the euglycemic insulin clamp. Diabetes Care. 1999;22(9):1462-1470.

7. DeFronzo RA, Tobin JD, Andres R. Glucose clamp technique: a method for quantifying insulin secretion and resistance. Am J Physiol. 1979;237(3):E214-E223.

8. Shen SW, Reaven GM, Farquhar JW. Comparison of impedance to insulin-mediated glucose uptake in normal subjects and in subjects with latent diabetes. J Clin Invest. 1970;49(12):2151-2160.

9. Wildman RP, et al. The obese without cardiometabolic risk factor clustering and the normal weight with cardiometabolic risk factor clustering: prevalence and correlates of 2 phenotypes among the US population (NHANES 19992004). Arch Intern Med. 2008;168(15):1617-1624.

10. Karelis AD, Brochu M, Rabasa-Lhoret R. Can we identify metabolically healthy but obese individuals (MHO)? Diabetes Metab. 2004;30(6):569-572.

11. Meigs JB, et al. Body mass index, metabolic syndrome, and risk of type 2 diabetes or cardiovascular disease. J Clin Endocrinol Metab. 2006;91(8):2906-2912.

12. Aguilar-Salinas CA, et al. High adiponectin concentrations are associated with the metabolically healthy obese phenotype. JClin Endocrinol Metab. 2008;93(10):4075-4079.

13. Kimokoti RW, Judd SE, Shikany JM, Newby PK. Metabolically healthy obesity is not associated with food intake in white or black men. J Nutr. 2015;145(11):2551-2561.

14. Zheng R, Zhou D, Zhu Y. The long-term prognosis of cardiovascular disease and all-cause mortality for metabolically healthy obesity: a systematic review and meta-analysis. J Epidemiol Community Health. 2016;70(10):1024-1031.

15. Ogorodnikova AD, Kim M, McGinn AP, Muntner P, Khan U, Wildman RP. Incident cardiovascular disease events in metabolically benign obese individuals. Obesity (Silver Spring). 2012;20(3):651-659.

16. Karelis AD, Rabasa-Lhoret R. Inclusion of $\mathrm{C}$-reactive protein in the identification of metabolically healthy but obese (MHO) individuals. Diabetes Metab. 2008;34(2):183-184.

17. Calori G, et al. Prevalence, metabolic features, and prognosis of metabolically healthy obese
Italian individuals: the Cremona Study. Diabetes Care. 2011;34(1):210-215.

18. Straznicky NE, et al. Blunted sympathetic neural response to oral glucose in obese subjects with the insulin-resistant metabolic syndrome. Am J Clin Nutr. 2009;89(1):27-36.

19. Stefan N, et al. Identification and characterization of metabolically benign obesity in humans. Arch Intern Med. 2008;168(15):1609-1616.

20. Brochu M, et al. What are the physical characteristics associated with a normal metabolic profile despite a high level of obesity in postmenopausal women? J Clin Endocrinol Metab. 2001;86(3):1020-1025.

21. Klöting N, et al. Insulin-sensitive obesity. Am J Physiol Endocrinol Metab. 2010;299(3):E506-E515.

22. Fabbrini E, et al. Association between specific adipose tissue CD4+ T-cell populations and insulin resistance in obese individuals. Gastroenterology. 2013;145(2):366-374.e1.

23. Karelis AD, et al. The metabolically healthy but obese individual presents a favorable inflammation profile. J Clin Endocrinol Metab. 2005;90(7):4145-4150.

24. Abbasi F, et al. Discrimination between obesity and insulin resistance in the relationship with adiponectin. Diabetes. 2004;53(3):585-590.

25. Echouffo-Tcheugui JB, et al. Natural history of obesity subphenotypes: dynamic changes over two decades and prognosis in the Framingham Heart Study. J Clin Endocrinol Metab. 2019;104(3):738-752.

26. Gómez-Ambrosi J, et al. Increased cardiometabolic risk factors and inflammation in adipose tissue in obese subjects classified as metabolically healthy. Diabetes Care. 2014;37(10):2813-2821.

27. Pajunen P, et al. Metabolically healthy and unhealthy obesity phenotypes in the general pop- 
ulation: the FIN-D2D Survey. BMC Public Health. 2011;11:754

28. Mongraw-Chaffin M, et al. Metabolically healthy obesity, transition to metabolic syndrome, and cardiovascular risk. J Am Coll Cardiol. 2018;71(17):1857-1865.

29. Austin MA, King MC, Vranizan KM, Krauss RM. Atherogenic lipoprotein phenotype. A proposed genetic marker for coronary heart disease risk. Circulation. 1990;82(2):495-506.

30. Jung SH, Jung CH, Reaven GM, Kim SH. Adapting to insulin resistance in obesity: role of insulin secretion and clearance. Diabetologia. 2018;61(3):681-687.

31. Ferrannini E, Natali A, Bell P, Cavallo-Perin P, Lalic N, Mingrone G. Insulin resistance and hypersecretion in obesity. European Group for the Study of Insulin Resistance (EGIR). JClin Invest. 1997;100(5):1166-1173.

32. Kuk JL, Ardern CI. Are metabolically normal but obese individuals at lower risk for all-cause mortality? Diabetes Care. 2009;32(12):2297-2299.

33. van Vliet-Ostaptchouk JV, et al. The prevalence of metabolic syndrome and metabolically healthy obesity in Europe: a collaborative analysis of ten large cohort studies. BMC Endocr Disord. 2014;14:9.

34. Ul-Haq Z, Mackay DF, Fenwick E, Pell JP. Impact of metabolic comorbidity on the association between body mass index and health-related quality of life: a Scotland-wide cross-sectional study of 5,608 participants. BMC Public Health. 2012;12:143.

35. Slagter SN, et al. Dietary patterns and physical activity in the metabolically (un)healthy obese: the Dutch Lifelines cohort study. Nutr J. 2018;17(1):18

36. Velho S, Paccaud F, Waeber G, Vollenweider P, Marques-Vidal P. Metabolically healthy obesity: different prevalences using different criteria. Eur J Clin Nutr. 2010;64(10):1043-1051.

37. Hinnouho GM, et al. Metabolically healthy obesity and the risk of cardiovascular disease and type 2 diabetes: the Whitehall II cohort study. Eur Heart J. 2015;36(9):551-559.

38. Hinnouho GM, Czernichow S, Dugravot A, Batty GD, Kivimaki M, Singh-Manoux A. Metabolically healthy obesity and risk of mortality: does the definition of metabolic health matter? Diabetes Care. 2013;36(8):2294-2300.

39. Lin H, Zhang L, Zheng R, Zheng Y. The prevalence, metabolic risk and effects of lifestyle intervention for metabolically healthy obesity: a systematic review and meta-analysis: a PRISMAcompliant article. Medicine (Baltimore). 2017;96(47):e8838.

40. Goday A, et al. Prevalence and clinical characteristics of metabolically healthy obese individuals and other obese/non-obese metabolic phenotypes in a working population: results from the Icaria study. BMC Public Health. 2016;16:248.

41. Misra A, Vikram NK. Insulin resistance syndrome (metabolic syndrome) and obesity in Asian Indians: evidence and implications. Nutrition. 2004;20(5):482-491.

42. Kouvari M, et al. Transition from metabolically benign to metabolically unhealthy obesity and 10-year cardiovascular disease incidence:
The ATTICA cohort study. Metab Clin Exp. 2019;93:18-24.

43. Shea JL, Randell EW, Sun G. The prevalence of metabolically healthy obese subjects defined by $\mathrm{BMI}$ and dual-energy X-ray absorptiometry. Obesity (Silver Spring). 2011;19(3):624-630.

44. Katzmarzyk PT, Church TS, Janssen I, Ross R, Blair SN. Metabolic syndrome, obesity, and mortality: impact of cardiorespiratory fitness. Diabetes Care. 2005;28(2):391-397.

45. Bell JA, Hamer M, Sabia S, Singh-Manoux A, Batty GD, Kivimaki M. The natural course of healthy obesity over 20 years. J Am Coll Cardiol. 2015;65(1):101-102.

46. Achilike I, Hazuda HP, Fowler SP, Aung K, Lorenzo C. Predicting the development of the metabolically healthy obese phenotype. Int JObes (Lond). 2015;39(2):228-234.

47. Soriguer F, et al. Metabolically healthy but obese, a matter of time? Findings from the prospective Pizarra study. JClin Endocrinol Metab. 2013;98(6):2318-2325.

48. Appleton SL, et al. Diabetes and cardiovascular disease outcomes in the metabolically healthy obese phenotype: a cohort study. Diabetes Care. 2013;36(8):2388-2394.

49. Bell JA, Hamer M, Batty GD, Singh-Manoux A, Sabia S, Kivimäki M. Incidence of metabolic risk factors among healthy obese adults: 20 -year follow-up. J Am Coll Cardiol. 2015;66(7):871-873.

50. Guo F, Garvey WT. Cardiometabolic disease risk in metabolically healthy and unhealthy obesity: stability of metabolic health status in adults. Obesity (Silver Spring). 2016;24(2):516-525.

51. Hashimoto Y, Hamaguchi M, Fukuda T, Ohbora A, Kojima T, Fukui M. Fatty liver as a risk factor for progression from metabolically healthy to metabolically abnormal in non-overweight individuals. Endocrine. 2017;57(1):89-97.

52. Moussa $\mathrm{O}$, et al. Fate of the metabolically healthy obese-is this term a misnomer? A study from the Clinical Practice Research Datalink. Int JObes (Lond). 2019;43(5):1093-1101.

53. Schröder H, et al. Determinants of the transition from a cardiometabolic normal to abnormal overweight/obese phenotype in a Spanish population. Eur J Nutr. 2014;53(6):1345-1353.

54. Cui Z, Truesdale KP, Bradshaw PT, Cai J, Stevens J. Three-year weight change and cardiometabolic risk factors in obese and normal weight adults who are metabolically healthy: the atherosclerosis risk in communities study. Int JObes (Lond). 2015;39(8):1203-1208.

55. Espinosa De Ycaza AE, Donegan D, Jensen MD. Long-term metabolic risk for the metabolically healthy overweight/obese phenotype. Int JObes (Lond). 2018;42(3):302-309.

56. Bell JA, Kivimaki M, Hamer M. Metabolically healthy obesity and risk of incident type 2 diabetes: a meta-analysis of prospective cohort studies. Obes Rev. 2014;15(6):504-515.

57. Caleyachetty R, et al. Metabolically healthy obese and incident cardiovascular disease events among 3.5 million men and women. J Am Coll Cardiol. 2017;70(12):1429-1437.

58. Arnlöv J, Ingelsson E, Sundström J, Lind L. Impact of body mass index and the metabolic syndrome on the risk of cardiovascular disease and death in middle-aged men. Circulation. 2010;121(2):230-236

59. Eckel N, Meidtner K, Kalle-Uhlmann T, Stefan N, Schulze MB. Metabolically healthy obesity and cardiovascular events: a systematic review and meta-analysis. Eur J Prev Cardiol. 2016;23(9):956-966.

60. Hamer M, Stamatakis E. Metabolically healthy obesity and risk of all-cause and cardiovascular disease mortality. JClin Endocrinol Metab. 2012;97(7):2482-2488.

61. Twig G, et al. Diabetes risk among overweight and obese metabolically healthy young adults. Diabetes Care. 2014;37(11):2989-2995.

62. Guo F, Garvey WT. Development of a weighted cardiometabolic disease staging (CMDS) system for the prediction of future diabetes. JClin Endocrinol Metab. 2015;100(10):3871-3877.

63. Guo F, Moellering DR, Garvey WT. The progression of cardiometabolic disease: validation of a new cardiometabolic disease staging system applicable to obesity. Obesity (Silver Spring). 2014;22(1):110-118.

64. Hamer M, Johnson W, Bell JA. Improving risk estimates for metabolically healthy obesity and mortality using a refined healthy reference group. Eur JEndocrinol. 2017;177(2):169-174.

65. Johnson W, Bell JA, Robson E, Norris T, Kivimäki M, Hamer M. Do worse baseline risk factors explain the association of healthy obesity with increased mortality risk? Whitehall II Study. Int $J$ Obes (Lond). 2019;43(8):1578-1589.

66. Kuk JL, Rotondi M, Sui X, Blair SN, Ardern CI. Individuals with obesity but no other metabolic risk factors are not at significantly elevated allcause mortality risk in men and women. Clin Obes. 2018;8(5):305-312.

67. Wang B, et al. Dynamic status of metabolically healthy overweight/obesity and metabolically unhealthy and normal weight and the risk of type 2 diabetes mellitus: a cohort study of a rural adult Chinese population. Obes Res Clin Pract. 2018;12(1):61-71.

68. Reaven GM. Banting lecture 1988. Role of insulin resistance in human disease. Diabetes. 1988;37(12):1595-1607.

69. Bradley D, Magkos F, Klein S. Effects of bariatric surgery on glucose homeostasis and type 2 diabetes. Gastroenterology. 2012;143(4):897-912.

70. Succurro E, et al. Insulin secretion in metabolically obese, but normal weight, and in metabolically healthy but obese individuals. Obesity (Silver Spring). 2008;16(8):1881-1886.

71. Marini MA, et al. Metabolically healthy but obese women have an intermediate cardiovascular risk profile between healthy nonobese women and obese insulin-resistant women. Diabetes Care. 2007;30(8):2145-2147.

72. Bell JA, Hamer M, van Hees VT, SinghManoux A, Kivimäki M, Sabia S. Healthy obesity and objective physical activity. Am JClin Nutr. 2015;102(2):268-275.

73. Sun K, Kusminski CM, Scherer PE. Adipose tissue remodeling and obesity. JClin Invest. 2011;121(6):2094-2101.

74. Freedhoff Y, Hall KD. Weight loss diet studies: we need help not hype. Lancet. 2016;388(10047):849-851. 
75. Dhurandhar NV, et al. Energy balance measurement: when something is not better than nothing. Int JObes (Lond). 2015;39(7):1109-1113.

76. Chen DL, et al. Phenotypic characterization of insulin-resistant and insulin-sensitive obesity. JClin Endocrinol Metab. 2015;100(11):4082-4091.

77. Phillips CM, et al. Defining metabolically healthy obesity: role of dietary and lifestyle factors. PLOS One. 2013;8(10):e76188.

78. Kim HN, Song SW. Associations between macronutrient intakes and obesity/metabolic risk phenotypes: findings of the Korean national health and nutrition examination survey. Nutrients. 2019;11(3):E628.

79. Park YM, et al. Mediterranean diet, Dietary Approaches to Stop Hypertension (DASH) style diet, and metabolic health in U.S. adults. Clin Nutr. 2017;36(5):1301-1309.

80. Camhi SM, Whitney Evans E, Hayman LL, Lichtenstein AH, Must A. Healthy eating index and metabolically healthy obesity in U.S. adolescents and adults. Prev Med. 2015;77:23-27.

81. Green AK, Jacques PF, Rogers G, Fox CS, Meigs JB, McKeown NM. Sugar-sweetened beverages and prevalence of the metabolically abnormal phenotype in the Framingham Heart Study. Obesity (Silver Spring). 2014;22(5):E157-E163.

82. Hankinson AL, et al. Diet composition and activity level of at risk and metabolically healthy obese American adults. Obesity (Silver Spring). 2013;21(3):637-643.

83. Karstoft K, Pedersen BK. Exercise and type 2 diabetes: focus on metabolism and inflammation. Immunol Cell Biol. 2016;94(2):146-150.

84. Messier V, Karelis AD, Prud'homme D, Primeau V, Brochu M, Rabasa-Lhoret R. Identifying metabolically healthy but obese individuals in sedentary postmenopausal women. Obesity (Silver Spring). 2010;18(5):911-917.

85. de Rooij BH, et al. Physical activity and sedentary behavior in metabolically healthy versus unhealthy obese and non-obese individuals - the Maastricht Study. PLoS One. 2016;11(5):e0154358.

86. Camhi SM, Waring ME, Sisson SB, Hayman LL, Must A. Physical activity and screen time in metabolically healthy obese phenotypes in adolescents and adults. JObes. 2013;2013:984613.

87. Ortega FB, et al. Role of physical activity and fitness in the characterization and prognosis of the metabolically healthy obesity phenotype: a systematic review and meta-analysis. Prog Cardiovasc Dis. 2018;61(2):190-205.

88. Arble DM, et al. Impact of sleep and circadian disruption on energy balance and diabetes: a summary of workshop discussions. Sleep. 2015;38(12):1849-1860.

89. Ryu JY, et al. Association between body size phenotype and sleep duration: Korean National Health and Nutrition Examination Survey V (KNHANES V). Metab Clin Exp. 2015;64(3):460-466.

90. Gangwisch JE, Malaspina D, Boden-Albala B, Heymsfield SB. Inadequate sleep as a risk factor for obesity: analyses of the NHANES I. Sleep. 2005;28(10):1289-1296.

91. Kanagasabai T, Dhanoa R, Kuk JL, Ardern CI. Association between sleep habits and metabolically healthy obesity in adults: a cross-sectional study. JObes. 2017;2017:5272984.

92. Zhang N, Chen Y, Guo X, Sun G, Dai D, Sun Y. Metabolic abnormalities, but not metabolically healthy obesity, are associated with left ventricular hypertrophy. Heart Lung Circ. 2017;26(3):251-257.

93. Zhang N, Chen Y, Guo X, Sun G, Sun Y. The prevalence and predictors of metabolically healthy obesity in obese rural population of China: a cross-sectional study. Psychol Health Med. 2017;22(3):303-309.

94. Cherqaoui R, et al. The metabolically healthy but obese phenotype in African Americans. JClin Hypertens (Greenwich). 2012;14(2):92-96.

95. Jennings CL, Lambert EV, Collins M, Joffe Y, Levitt NS, Goedecke JH. Determinants of insulinresistant phenotypes in normal-weight and obese Black African women. Obesity (Silver Spring). 2008;16(7):1602-1609.

96. Koster A, et al. Body fat distribution and inflammation among obese older adults with and without metabolic syndrome. Obesity (Silver Spring). 2010;18(12):2354-2361.

97. Hayes L, Pearce MS, Firbank MJ, Walker M, Taylor R, Unwin NC. Do obese but metabolically normal women differ in intra-abdominal fat and physical activity levels from those with the expected metabolic abnormalities? A crosssectional study. BMC Public Health. 2010;10:723.

98. Kim LJ, et al. Associations of visceral and liver fat with the metabolic syndrome across the spectrum of obesity: the AGES-Reykjavik study. Obesity (Silver Spring). 2011;19(6):1265-1271.

99. Korenblat, et al. Liver, muscle, and adipose tissue insulin action is directly related to intrahepatic triglyceride content in obese subjects. Gastroenterology. 2008;134(5):1369-1375.

100.Fabbrini E, Mohammed BS, Magkos F, Korenblat KM, Patterson BW, Klein S. Alterations in adipose tissue and hepatic lipid kinetics in obese men and women with nonalcoholic fatty liver disease. Gastroenterology. 2008;134(2):424-431.

101. Fabbrini $\mathrm{E}$, et al. Intrahepatic fat, not visceral fat, is linked with metabolic complications of obesity. Proc Natl Acad Sci U S A 2009;106(36):15430-15435.

102. McLaughlin T, et al. Enhanced proportion of small adipose cells in insulin-resistant vs insulin-sensitive obese individuals implicates impaired adipogenesis. Diabetologia. 2007;50(8):1707-1715.

103. Almuraikhy S, et al. Interleukin-6 induces impairment in human subcutaneous adipogenesis in obesity-associated insulin resistance. Diabetologia. 2016;59(11):2406-2416.

104. Yang X, et al. Evidence of impaired adipogenesis in insulin resistance. Biochem Biophys Res Commun. 2004;317(4):1045-1051.

105. Park HT, et al. The relationship between fat depot-specific preadipocyte differentiation and metabolic syndrome in obese women. Clin Endocrinol (Oxf). 2012;76(1):59-66.

106. Allister $\mathrm{CA}$, et al. In vivo $2 \mathrm{H}_{2} \mathrm{O}$ administration reveals impaired triglyceride storage in adipose tissue of insulin-resistant humans. J Lipid Res. 2015;56(2):435-439.

107. White UA, Fitch MD, Beyl RA, Hellerstein MK, Ravussin E. Association of in vivo adipose tissue cellular kinetics with markers of meta- bolic health in humans. J Clin Endocrinol Metab. 2017;102(7):2171-2178.

108. Liss KHH, et al. Metabolic importance of adipose tissue monoacylglycerol acyltransferase 1 in mice and humans. JLipid Res. 2018;59(9):1630-1639.

109. Herman MA, et al. A novel ChREBP isoform in adipose tissue regulates systemic glucose metabolism. Nature. 2012;484(7394):333-338.

110. Fabbrini E, et al. Metabolically normal obese people are protected from adverse effects following weight gain. JClin Invest. 2015;125(2):787-795.

111. Ghaben AL, Scherer PE. Adipogenesis and metabolic health. Nat Rev Mol Cell Biol. 2019;20(4):242-258.

112. Laforest $\mathrm{S}$, et al. Comparative analysis of three human adipocyte size measurement methods and their relevance for cardiometabolic risk. Obesity (Silver Spring). 2017;25(1):122-131.

113. Xu X, Grijalva A, Skowronski A, van Eijk M, Serlie MJ, Ferrante AW. Obesity activates a program of lysosomal-dependent lipid metabolism in adipose tissue macrophages independently of classic activation. Cell Metab. 2013;18(6):816-830.

114. McLaughlin T, et al. Subcutaneous adipose cell size and distribution: relationship to insulin resistance and body fat. Obesity (Silver Spring). 2014;22(3):673-680.

115. Pasarica $M$, et al. Lower total adipocyte number but no evidence for small adipocyte depletion in patients with type 2 diabetes. Diabetes Care. 2009;32(5):900-902.

116. Weyer C, Foley JE, Bogardus C, Tataranni PA, Pratley RE. Enlarged subcutaneous abdominal adipocyte size, but not obesity itself, predicts type II diabetes independent of insulin resistance. Diabetologia. 2000;43(12):1498-1506.

117. Rydén M, Andersson DP, Bergström IB, Arner P. Adipose tissue and metabolic alterations: regional differences in fat cell size and number matter, but differently: a cross-sectional study. JClin Endocrinol Metab. 2014;99(10):E1870-E1876.

118. Cotillard A, et al. Adipocyte size threshold matters: link with risk of type 2 diabetes and improved insulin resistance after gastric bypass. J Clin Endocrinol Metab. 2014;99(8):E1466-E1470.

119. O'Connell J, et al. The relationship of omental and subcutaneous adipocyte size to metabolic disease in severe obesity. PLoS One. 2010;5(4):e9997.

120.Hodson L, Humphreys SM, Karpe F, Frayn KN. Metabolic signatures of human adipose tissue hypoxia in obesity. Diabetes. 2013;62(5):1417-1425.

121. Littleton SW, Tulaimat A. The effects of obesity on lung volumes and oxygenation. Respir Med. 2017;124:15-20.

122. McQuaid SE, et al. Downregulation of adipose tissue fatty acid trafficking in obesity: a driver for ectopic fat deposition? Diabetes. 2011;60(1):47-55.

123. Pasarica M, et al. Reduced adipose tissue oxygenation in human obesity: evidence for rarefaction, macrophage chemotaxis, and inflammation without an angiogenic response. Diabetes. 2009;58(3):718-725.

124.Pasarica M, Rood J, Ravussin E, Schwarz JM, Smith SR, Redman LM. Reduced oxygenation in human obese adipose tissue is associated with impaired insulin suppression of lipolysis. J Clin Endocrinol Metab. 2010;95(8):4052-4055. 
125. Goossens GH, et al. Increased adipose tissue oxygen tension in obese compared with lean men is accompanied by insulin resistance, impaired adipose tissue capillarization, and inflammation. Circulation. 2011;124(1):67-76.

126. Weisberg SP, McCann D, Desai M, Rosenbaum M, Leibel RL, Ferrante AW. Obesity is associated with macrophage accumulation in adipose tissue. J Clin Invest. 2003;112(12):1796-1808.

127. Helmlinger G, Yuan F, Dellian M, Jain RK. Interstitial $\mathrm{pH}$ and $\mathrm{pO} 2$ gradients in solid tumors in vivo: high-resolution measurements reveal a lack of correlation. Nat Med. 1997;3(2):177-182.

128. Seo JB, et al. Knockdown of ANT2 reduces adipocyte hypoxia and improves insulin resistance in obesity. Nat Metab. 2019;1(1):86-97.

129. Lawler HM, Underkofler CM, Kern PA, Erickson C, Bredbeck B, Rasouli N. Adipose tissue hypoxia, inflammation, and fibrosis in obese insulinsensitive and obese insulin-resistant subjects. J Clin Endocrinol Metab. 2016;101(4):1422-1428.

130.Goossens GH, Vogel MAA, Vink RG, Mariman EC, van Baak MA, Blaak EE. Adipose tissue oxygenation is associated with insulin sensitivity independently of adiposity in obese men and women. Diabetes Obes Metab. 2018;20(9):2286-2290.

131. Henegar C, et al. Adipose tissue transcriptomic signature highlights the pathological relevance of extracellular matrix in human obesity. Genome Biol. 2008;9(1):R14.

132. Spencer M, et al. Adipose tissue extracellular matrix and vascular abnormalities in obesity and insulin resistance. JClin Endocrinol Metab. 2011;96(12):E1990-E1998.

133. Michaud A, et al. Relevance of omental pericellular adipose tissue collagen in the pathophysiology of human abdominal obesity and related cardiometabolic risk. Int J Obes (Lond). 2016;40(12):1823-1831.

134. Pasarica M, et al. Adipose tissue collagen VI in obesity. JClin Endocrinol Metab. 2009;94(12):5155-5162.

135. Divoux A, et al. Fibrosis in human adipose tissue: composition, distribution, and link with lipid metabolism and fat mass loss. Diabetes. 2010;59(11):2817-2825.

136. Yoshino J, Patterson BW, Klein S. Adipose tissue CTGF expression is associated with adiposity and insulin resistance in humans. Obesity (Silver Spring). 2019;27(6):957-962

137. Magkos F, et al. Effects of moderate and subsequent progressive weight loss on metabolic function and adipose tissue biology in humans with obesity. Cell Metab. 2016;23(4):591-601.

138. Dankel SN, et al. COL6A3 expression in adipocytes associates with insulin resistance and depends on PPAR $\gamma$ and adipocyte size. Obesity (Silver Spring). 2014;22(8):1807-1813.

139. Reggio S, et al. Increased basement membrane components in adipose tissue during obesity: links with TGF $\beta$ and metabolic phenotypes. J Clin Endocrinol Metab. 2016;101(6):2578-2587.

140.Sun K, Tordjman J, Clément K, Scherer PE. Fibrosis and adipose tissue dysfunction. Cell Metab. 2013;18(4):470-477.

141. Lee YS, Wollam J, Olefsky JM. An integrated view of immunometabolism. Cell. 2018;172(1-2):22-40.

142. Hotamisligil GS, Shargill NS, Spiegelman BM.
Adipose expression of tumor necrosis factoralpha: direct role in obesity-linked insulin resistance. Science. 1993;259(5091):87-91.

143. Xu H, et al. Chronic inflammation in fat plays a crucial role in the development of obesityrelated insulin resistance. J Clin Invest. 2003;112(12):1821-1830.

144. Bigornia SJ, et al. Relation of depot-specific adipose inflammation to insulin resistance in human obesity. Nutr Diabetes. 2012;2:e30.

145. Esser N, et al. Obesity phenotype is related to NLRP3 inflammasome activity and immunological profile of visceral adipose tissue. Diabetologia. 2013;56(11):2487-2497.

146. McLaughlin T, et al. Insulin resistance is associated with a modest increase in inflammation in subcutaneous adipose tissue of moderately obese women. Diabetologia. 2008;51(12):2303-2308.

147. Wentworth JM, et al. Pro-inflammatory

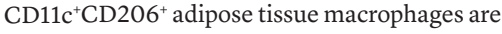
associated with insulin resistance in human obesity. Diabetes. 2010;59(7):1648-1656.

148. Pandolfi JB, et al. ATP-induced inflammation drives tissue-resident Th17 cells in metabolically unhealthy obesity. J Immunol. 2016;196(8):3287-3296.

149. McLaughlin T, et al. T-cell profile in adipose tissue is associated with insulin resistance and systemic inflammation in humans. Arterioscler Thromb Vasc Biol. 2014;34(12):2637-2643.

150. Das SK, Ma L, Sharma NK. Adipose tissue gene expression and metabolic health of obese adults. Int JObes (Lond). 2015;39(5):869-873.

151. Qatanani M, et al. Inverse regulation of inflammation and mitochondrial function in adipose tissue defines extreme insulin sensitivity in morbidly obese patients. Diabetes. 2013;62(3):855-863.

152. Shin MJ, Hyun YJ, Kim OY, Kim JY, Jang Y, Lee $\mathrm{JH}$. Weight loss effect on inflammation and LDL oxidation in metabolically healthy but obese (MHO) individuals: low inflammation and LDL oxidation in MHO women. Int JObes (Lond). 2006;30(10):1529-1534.

153. Wildman RP, et al. Body size phenotypes and inflammation in the Women's Health Initiative Observational Study. Obesity (Silver Spring). 2011;19(7):1482-1491.

154. Jung $\mathrm{CH}$, et al. The risk of incident type 2 diabetes in a Korean metabolically healthy obese population: the role of systemic inflammation. J Clin Endocrinol Metab. 2015;100(3):934-941.

155. Amouzou C, et al. Skeletal muscle insulin resistance and absence of inflammation characterize insulin-resistant grade I obese women. PLoS One. 2016;11(4):e0154119.

156. Cătoi AF, et al. Metabolically healthy versus unhealthy morbidly obese: chronic inflammation, nitro-oxidative stress, and insulin resistance. Nutrients. 2018;10(9):E1199.

157. Iglesias Molli AE, et al. Metabolically healthy obese individuals present similar chronic inflammation level but less insulin-resistance than obese individuals with metabolic syndrome. PLoS One. 2017;12(12):e0190528.

158. Ying W, et al. Adipose tissue macrophagederived exosomal miRNAs can modulate in vivo and in vitro insulin sensitivity. Cell. 2017;171(2):372-384.e12.
159. Boden G, Chen X, Ruiz J, White JV, Rossetti L. Mechanisms of fatty acid-induced inhibition of glucose uptake. J Clin Invest. 1994;93(6):2438-2446.

160. Kruszynska YT, Olefsky JM, Frias JP. Effect of obesity on susceptibility to fatty acid-induced peripheral tissue insulin resistance. Metab Clin Exp. 2003;52(2):233-238.

161. Van Pelt DW, Newsom SA, Schenk S, Horowitz JF. Relatively low endogenous fatty acid mobilization and uptake helps preserve insulin sensitivity in obese women. Int JObes (Lond). 2015;39(1):149-155.

162.Arner P, Rydén M. Fatty acids, obesity and insulin resistance. Obes Facts. 2015;8(2):147-155.

163. Gauthier MS, et al. Increased subcutaneous adipose tissue expression of genes involved in glycerolipid-fatty acid cycling in obese insulinresistant versus -sensitive individuals. JClin Endocrinol Metab. 2014;99(12):E2518-E2528.

164. Bickerton AS, et al. Adipose tissue fatty acid metabolism in insulin-resistant men. Diabetologia. 2008;51(8):1466-1474.

165. Karpe F, Dickmann JR, Frayn KN. Fatty acids, obesity, and insulin resistance: time for a reevaluation. Diabetes. 2011;60(10):2441-2449.

166. Conte C, Fabbrini E, Kars M, Mittendorfer B, Patterson BW, Klein S. Multiorgan insulin sensitivity in lean and obese subjects. Diabetes Care 2012;35(6):1316-1321.

167. Mittendorfer B, Magkos F, Fabbrini E, Mohammed BS, Klein S. Relationship between body fat mass and free fatty acid kinetics in men and women. Obesity (Silver Spring). 2009;17(10):1872-1877.

168. Nielsen S, Guo Z, Albu JB, Klein S, O'Brien PC, Jensen MD. Energy expenditure, sex, and endogenous fuel availability in humans. J Clin Invest. 2003;111(7):981-988.

169. Nuutila P, et al. Gender and insulin sensitivity in the heart and in skeletal muscles. Studies using positron emission tomography. Diabetes. 1995;44(1):31-36.

170. Ter Horst KW, et al. Sexual dimorphism in hepatic, adipose tissue, and peripheral tissue insulin sensitivity in obese humans. Front Endocrinol (Lausanne). 2015;6:182.

171. Frias JP, Macaraeg GB, Ofrecio J, Yu JG, Olefsky JM, Kruszynska YT. Decreased susceptibility to fatty acid-induced peripheral tissue insulin resistance in women. Diabetes. 2001;50(6):1344-1350.

172. Bergman RN, Iyer MS. Indirect regulation of endogenous glucose production by insulin: the single gateway hypothesis revisited. Diabetes. 2017;66(7):1742-1747.

173. Tschritter O, et al. Plasma adiponectin concentrations predict insulin sensitivity of both glucose and lipid metabolism. Diabetes. 2003;52(2):239-243.

174. Martínez-Larrad MT, Corbatón Anchuelo A, De Prado N, Ibarra Rueda JM, Gabriel R, SerranoRíos M. Profile of individuals who are metabolically healthy obese using different definition criteria. A population-based analysis in the Spanish population. PLoS One. 2014;9(9):e106641.

175. Ahl S, et al. Adiponectin levels differentiate metabolically healthy vs unhealthy among obese and nonobese white individuals. JClin Endocrinol Metab. 2015;100(11):4172-4180.

176. Doumatey AP, Bentley AR, Zhou J, Huang H, 
Adeyemo A, Rotimi CN. Paradoxical hyperadiponectinemia is associated with the metabolically healthy obese (MHO) phenotype in African Americans. J Endocrinol Metab. 2012;2(2):51-65.

177. Murdolo G, Hammarstedt A, Schmelz M, Jansson $\mathrm{PA}$, Smith U. Acute hyperinsulinemia differentially regulates interstitial and circulating adiponectin oligomeric pattern in lean and insulin-resistant, obese individuals. J Clin Endocrinol Metab. 2009;94(11):4508-4516.

178. Elisha B, Karelis AD, Imbeault P, Rabasa-Lhoret R. Effects of acute hyperinsulinaemia on total and high-molecular-weight adiponectin concentration in metabolically healthy but obese postmenopausal women: a Montreal-Ottawa New Emerging Team (MONET) study. Diabetes Metab. 2010;36(4):319-321.

179. Loos RJF, Kilpeläinen TO. Genes that make you fat, but keep you healthy. J Intern Med.
2018;284(5):450-463.

180.Bouter KE, van Raalte DH, Groen AK, Nieuwdorp M. Role of the gut microbiome in the pathogenesis of obesity and obesity-related metabolic dysfunction. Gastroenterology. 2017;152(7):1671-1678.

181. Allin KH, et al. Aberrant intestinal microbiota in individuals with prediabetes. Diabetologia. 2018;61(4):810-820.

182. Tilg H, Kaser A. Gut microbiome, obesity, and metabolic dysfunction. JClin Invest. 2011;121(6):2126-2132.

183. Lynch LA, O'Connell JM, Kwasnik AK, Cawood TJ, O'Farrelly C, O'Shea DB. Are natural killer cells protecting the metabolically healthy obese patient? Obesity (Silver Spring). 2009;17(3):601-605.

184.Grundy SM, et al. Diagnosis and management of the metabolic syndrome: an American Heart Association/National Heart, Lung, and Blood Institute scientific statement: Executive Summa- ry. Crit Pathw Cardiol. 2005;4(4):198-203.

185. Alberti KG, et al. Harmonizing the metabolic syndrome: a joint interim statement of the International Diabetes Federation Task Force on Epidemiology and Prevention; National Heart, Lung, and Blood Institute; American Heart Association; World Heart Federation; International Atherosclerosis Society; and International Association for the Study of Obesity. Circulation. 2009;120(16):1640-1645.

186.Al-Khalidi B, Kimball SM, Kuk JL, Ardern CI. Metabolically healthy obesity, vitamin D, and all-cause and cardiometabolic mortality risk in NHANES III. Clin Nutr. 2019;38(2):820-828.

187. Genelhu VA, Celoria BM, Duarte SF, Cabello PH, Francischetti EA. Not all obese subjects of multiethnic origin are at similar risk for developing hypertension and type 2 diabetes. Eur J Intern Med. 2009;20(3):289-295. 